\section{BADN PRESIDENTIAL COLUMN}

\author{
By Jacqui Elsden
}

()$^{n}$ ne year on from Lockdown 1.0, I have received my first COVID-19 vaccination and the sun is shining! I am thankful for these two things as for me it represents hope.

Being President of the British Association of Dental Nurses (BADN) since 2019, I have spent most of my role in various lockdowns, national and local! You would initially think this might have been a quiet time but I can honestly say it has been the polar opposite! Much has been happening online with many colleagues and BADN members, both professionally and socially. The social events for members have provided that much-needed boost to keep going in a difficult working climate.

In 2020, one of the main social events celebrated by BADN was our $80^{\text {th }}$ birthday, which we took online. It came at just the right time for many of our members as it was an opportunity to celebrate BADN's longevity of existence and therefore support, at a time when it felt good to see each other in virtual reality. Many 'in-person' events had been cancelled last year and members appreciated BADN reaching out to them in support of their mental health.

Following on from our $80^{\text {th }}$ birthday celebrations, we have continued to provide monthly social events with a small element of CPD, to allow members and non-members to meet up in not only a professional sense but more importantly in a social sense. We called these our 'Coffee Catch Ups' and they take place on the last Saturday of each month, with March 2021 being the sixth event, and are free to attend.

The Catch Ups are designed to give dental nurses a chance to network, chat with and ask questions of myself, of the Executive Committee, of members and of staff, and to be kept up to date with new developments. They usually last two hours and within that time we offer 30 minutes of verifiable CPD which is related to the invited monthly guest speaker. I felt there was a need for a forum where dental nurses could talk to each other - and to us, receive updated accurate information... and perhaps have a little fun!

We commenced in October last year and our speakers have delivered engaging

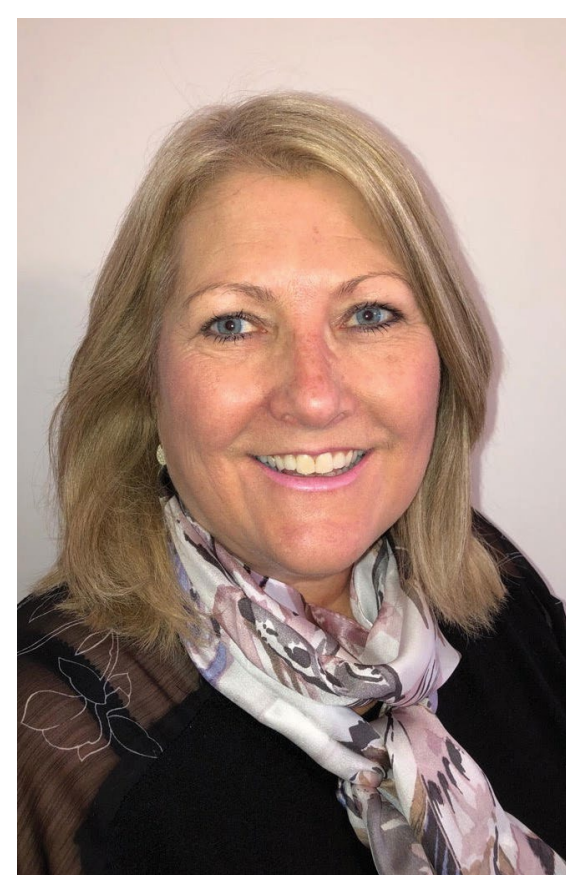

presentations on the nuances of indemnity and how to make the right choices; BADN's Rewards Scheme (money saving offers); interactive sessions for teambuilding and understanding team archetypes; guided meditations and dealing with stress; the nature of Leading Up (how to understand and support our leaders, to enable success of the leader, the led and the entire team more effectively) and how to approach and support people subjected to domestic abuse.

Our first speaker in 2021 was Alex Norris MP, Shadow Minister for Primary Care. Alex wanted to listen to dental nurses' stories first hand, regarding the effect of the pandemic upon themselves, their families and their working lives. Alex is supporting our campaign for the 'Recognition of Dental Nurses' Contribution to Dentistry' as we continue to raise awareness about how many dental nurses continue to feel undervalued within the profession.

Due to the continued success of our informal Coffee Catch Ups, you have lots more to look forward to in the coming months. All dental nurses, member or not, may sign up to our newsletters and automatically be informed about the programme at www.badn.org.uk.

Please do contact us at enquiries@badn. org.uk or visit our website www.badn.org. uk.

\section{GUM DISEASE LINKED TO COVID-19 COMPLICATIONS}

A study published in the Journal of Clinical Periodontology has found that people with advanced gum disease are much more likely to suffer complications from coronavirus, including being more likely to require a ventilator and to

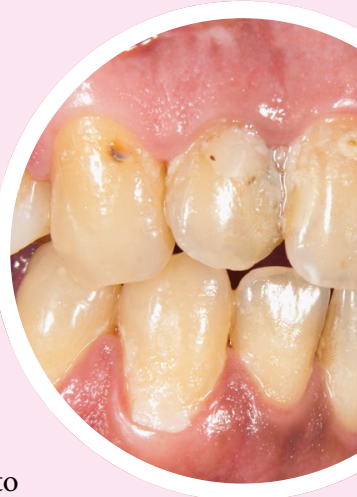
die from the disease.

The research, which examined more than 500 patients, found those with severe gum disease were up to nine times more likely to die from COVID-19. It also found that patients with the disease were nearly five times more likely to need assisted ventilation.

Coronavirus has now infected around 4.1 million people in the UK. ${ }^{2}$ An estimated $90 \%$ of UK adults have some form of gum disease. $^{3}$

The Oral Health Foundation is keen to highlight the importance of taking early action against the signs of gum disease, following research that suggests far too many people ignore it.

Latest figures collected by the charity show almost one-in-five Brits (19\%) immediately stop brushing the bleeding area and nearly one in ten (8\%) stop brushing altogether. ${ }^{4}$

\section{References}

1. Marouf N, Cai W, Said K N et al. Association between periodontitis and severity of COVID-19 infection: A casecontrol study. J Clin Periodontol 2021; https://doi.org/10.1111/jcpe.13435.

2. Coronavirus (COVID-19) in the UK. Daily update. Available at: https:// coronavirus.data.gov.uk/ (accessed March 2021).

3. Grant M. Nearly all of us have gum disease - so let's do something about it. University of Birmingham, 28 May 2015. Available at: https://www.birmingham. ac.uk/news/thebirminghambrief/ items/2015/05/nearly-all-of-us-havegum-disease-28-05-15.aspx (accessed February 2021)

4. Oral Health Foundation. National Smile Month Survey 2019. UK: Atomik Research, 2019. 